\title{
Cognitive functioning correlates of self-esteem and health locus of control in schizophrenia
}

\author{
This article was published in the following Dove Press journal: \\ Neuropsychiatric Disease and Treatment \\ 25 October 2013 \\ Number of times this article has been viewed
}

\author{
Chien-Shu Wang' \\ Jo Yung-Wei Wu ${ }^{2}$ \\ Wei-Chung Chang ${ }^{3}$ \\ Shu-Ping Chuang' \\ 'Department of Psychiatry, Zuoying \\ Branch of Kaohsiung Armed Forces \\ General Hospital, Kaohsiung, Taiwan; \\ ${ }^{2}$ Institute of Allied Health Sciences, \\ College of Medicine, National Cheng \\ Kung University, Tainan, Taiwan; \\ ${ }^{3} \mathrm{Hsin}$-jia Psychotherapy Clinic, Taitung \\ County, Taiwan
}

Aim: The study aimed to investigate the relationship among sociodemographic factors, neurocognitive factors, self-esteem, and health locus of control in patients diagnosed with schizophrenia. We examined the self-esteem, internal health locus of control, and external health locus of control through sociodemographic and neurocognitive factors.

Methods: Forty-six schizophrenic patients and 31 healthy residents from the community or hospital were recruited as the control group. All subjects participated in the self-esteem questionnaire, health locus of control questionnaire, and a series of neuropychological measures.

Results: Multiple regression analysis revealed that inhibition of attention and external health locus of control were predictors for self-esteem $(r=-0.30, P<0.05 ; r=0.41, P<0.01)$; inhibition of attention and external health locus of control were contributors for internal health locus of control ( $r=-0.43, P<0.01 ; r=0.61, P<0.001)$; and education was related to external health locus of control $(r=-0.31, P<0.05)$.

Conclusion: The current study integrated background characteristics and cognitive function to better understand the impact of self-esteem and health locus of control in schizophrenia. The findings indicated that inhibition of attention, external health locus of control, and education contributed to self-esteem, internal health locus of control and external health locus of control. However, the overall predicted variance accounted for by these predictors was small; thus, further research is necessary to examine imperative variables related with self-esteem and health locus of control in schizophrenia.

Keywords: cognitive functioning, self-esteem, internal health locus of control, external health locus of control, schizophrenia

\section{Introduction}

Schizophrenia patients may experience alterations in self concept and thus face difficulties in dealing with self-esteem. ${ }^{1-3}$ In recent decades, self-esteem has emerged as an essential concept possibly related to the psychopathology and treatment of patients with severe psychiatric illness. ${ }^{1,4-6}$ Brown et $\mathrm{al}^{7}$ found that there was a strong negative association between self-evaluation and interpersonal relationship, including parents, children, and close friends. Further studies have demonstrated that schizophrenia patients with lower self-esteem experienced a higher risk of suicidal ideation, more depression, and poor psychosocial functioning. ${ }^{8-10}$ Accordingly, negative evaluations of the self have been correlated with mental health problems. ${ }^{11,12}$ On the other hand, people with higher self-esteem and internal health locus of control usually have a positive self-concept and maintain a better mood. ${ }^{13-17}$ Several studies have found higher self-esteem in relation to better medication compliance and treatment adherence. ${ }^{18,19}$ 
Health locus of control is essential for maintaining a healthy life environment, and assesses the extent to which individuals believe that their health is related to their own behaviors (internal health locus of control) or to some external consequences (external health locus of control) ${ }^{20}$ A person with a high internal locus of control may feel more empowered to convert to healthy behaviors, while on the other hand, high external locus of control is often correlated with psychosocial maladjustment. ${ }^{21,22}$ People with schizophreniaspectrum disorders and bipolar disorder were found to be more likely to have a health locus of control determined by powerful others and chance when compared to people with nonpsychotic mental illness. ${ }^{23}$

Neurocognitive variables, such as executive functioning have not been associated with the self-esteem of schizophrenia; ${ }^{24}$ however, researchers have found that schizophrenia patients with intact executive functioning have a higher level of self-esteem. ${ }^{25}$ Previous studies indicated that patients, diagnosed under the schizophrenia spectrum disorder, who have poor attention tend to score lower in self-esteem and have a greater acceptance of stigma. ${ }^{24,26}$ Additional neurocognitive variables of schizophrenia or schizoaffective disorder have also been examined, showing deficits in immediate memory, language, delayed memory, verbal ability, processing speed, visual working memory, and verbal memory when compared with healthy samples..$^{27,28}$

In sum, self-esteem and health locus of control during the long-term rehabilitation process of schizophrenia are important in understanding their experiences and in implicating further treatment. The present study aimed at identifying correlates of these self-concepts and health locus of control from a broad range of sociodemographic and neuropsychological factors.

\section{Methods}

\section{Participants}

Forty-six schizophrenia outpatients were interviewed using the Structured Clinical Interview for Diagnostic and Statistical Manual of Mental Disorders Fourth Edition (DSM-IV) Diagnoses ${ }^{29}$ from the department of psychiatry at the Zuoying Branch of Kaohsiung Armed Forces General Hospital in Taiwan. Two psychiatrists made the diagnoses independently. When an inconsistent diagnosis occurred between the original two psychiatrists, an assessment made by a third psychiatrist was incorporated to reach a consensus. All participants were receiving ongoing medical treatment. Participants who were experiencing acute psychotic symptoms (including mood disorders) or had a history of mental retardation or who had participated in substance abuse or who had shown any neurological disorder in the preceding 6 months were excluded from the study. Clinical stability was defined as no acute hospitalizations or changes in medication in the previous month.

Thirty-one healthy adults were selected from a pool of participants who voluntarily participated in the neuropsychological assessment and questionnaire through several sources including word-of-mouth and advertisements in the community or in the hospital. None of them had any history of neurological or psychiatric disease, and none was taking any medication known to affect the central nervous system at the time of the study. Prior to receiving assessments, all participants gave written consent to participate in the study.

Twenty-three schizophrenic patients were being prescribed atypical antipsychotic medication at baseline and the other 23 schizophrenic patients were given typical antipsychotic medication.

The 46 schizophrenic patients in the study had a mean age of 41.3 years (standard deviation $[\mathrm{SD}]=8.9$ years) and a mean of 16.3 years duration of illness ( $\mathrm{SD}=8.5$ years). The onset age of illness was 25.2 years ( $\mathrm{SD}=7.4$ years). There were more males than females $(60.9 \%)$ in the patient group (however, this condition was inversed in the healthy control group). No significant differences were found between the genders on most sociodemographic and clinical characteristics, except for immediate face recognition memory, number of errors of crossmodal integration, and number of omission of inhibition (go/no-go 1-2) in the patient group. No significant gender differences were found on most sociodemographic and clinical characteristics among the healthy control group.

\section{Measurement}

\section{Rosenberg self-esteem scale (RSES)}

The Rosenberg self-esteem scale is a 10-item rating scale used to assess a person's overall evaluation of his or her worthiness as a human being. ${ }^{30}$ Responses are coded on a 4-point scale ranging from 1 (strongly disagree) to 4 (strongly agree). Items with negative statements are reverse scored and higher scores indicate higher self-esteem.

\section{Health locus of control questionnaire}

The health locus of control questionnaire consists of 13 items divided into two subscales..$^{31}$ Internal health locus of control assesses one's belief in their ability to influence an event. External health locus of control measures one's belief that their health status is the result of external factors. All items 
are scored on a Likert scale, ranging from 1 (completely disagree) to 4 (completely agree). The inter-rater reliability was 0.98 .

\section{Wisconsin Card Sorting Test}

The Wisconsin Card Sorting Test was originally developed to assess planning capacity, capacity of shifting cognitive strategies, and control of impulsive responses in reaction to environmental changes. ${ }^{32}$ Participants have to match a target card with one of four category cards according to different principles (eg, matched by color, form, and number in proper order). After each trial, a correct or incorrect feedback is given to the participant, indicating if they have matched the card appropriately. As the test progresses, there are unannounced shifts in the sorting principle which require the participant to change his or her approach. The test ends when the participant has completed six categories or 128 trials.

\section{Subtests of the Wechsler Memory Scale-Third Edition Manual}

The Wechsler Memory Scale-Third Edition Manual has been used widely for the evaluation of memory in adults. ${ }^{33}$

1. Faces Memory (I): This test presents 24 picture faces to the participant and requires them to memorize all of the faces and distinguish these faces in a 48-face item list.

2. Verbal Paired Associations Memory (I): This test requires the participant to memorize eight verbal paired associations and provide the correct verbal word pair.

3. Digit Span: Used to measure working memory, participants are presented with a series of digits (eg, digit span forward and backward) and immediate reiteration is required.

4. Spatial Span: It has been viewed as an indicator of working memory and visuospatial processing, and as a nonverbal version of Digit Span.

\section{Subtests of the test of attentional performance}

The tests of attention used in this study were developed and validated for the assessment of attentional deficits in children and adults with cerebral lesions. ${ }^{34}$ Participants are orally instructed to perform the computerized tasks. Tests were only performed when participants made no errors during the practice trials.

1. The alertness tasks: participants respond by pressing a button when a visual stimulus appeared on a computer screen. A total of 80 trials were undertaken. The task was constructed according to an A-B-B-A design in order to compensate for effects of fatigue; that is, the examination consists of four blocks (each with 20 target stimuli) in the sequence: (a) Run: without warning tone (b) Run: with warning tone (c) Run: with warning tone (d) Run: without warning tone.

2. The test of crossmodal integration: arrows directing up or down and high or low sounds are presented simultaneously. The participant is asked to press a response button as quickly as possible when a target stimulus occurs (eg, when the pitch of the tone and the direction of the arrow are in agreement). The task measures selective attention as the capacity to integrate sensory information of different modalities.

3. The flexibility task: the "set shifting" task requires the participant to place each hand on a separate response button while viewing a computer screen, on which a letter and a number are displayed simultaneously. The participant has to press the left or right button according to whether the target stimulus (eg, letter or number) appears to the left or the right of the center of the monitor.

4. The inhibition task: the task assesses the capacity to perform an appropriate reaction under time pressure and to simultaneously inhibit an inappropriate behavior response. Two forms of this test were administrated. 1) Test form " 1 of 2 :" an upright cross $(+)$ and a diagonal cross $(\times)$ are presented in an altering sequence on the screen. The participant has to press the button as quickly as possible whenever the diagonal cross appears. 2) Test form " 2 of 5:" a sequence of five squares with different patterns appears on the screen and two of these squares are defined as target stimulus, upon the appearance of which the participant presses the button as quickly as possible.

5. The incompatibility task: arrows pointing to the left or the right are presented briefly on the left or right side of the fixation point in the center of the monitor. The participants are required to press a response button as quickly as possible on the side indicated by the direction of the arrow. A compatible condition occurs when the side of arrow in the visual field and the side of the responding hand correspond. Incompatibility occurs when the side of arrow and the direction in which it points do not correspond.

\section{Statistical analysis}

All statistical analyses were carried out using SPSS version 12.0 (IBM Corporation, Armonk, NY, USA). We performed Pearson correlation tests among sociodemographic 
characteristics, neuropsychological variables, self-esteem, internal health locus of control, and external health locus of control. Comparisons of age, education, and marital status between the patient and control groups were performed using two sample $t$-tests or chi-square statistics as appropriate. Comparisons of clinical measures between patient and control groups were performed using one-way analysis of covariance, controlling age and education as covariates. Corrections for multiple testing were used according to the Bonferroni method. Significance at an alpha level of 0.05 was applied. Only significant variables were shown in the table. Stepwise regression analyses were performed to explore the relative contribution of each significant variable between self-esteem and health locus of control measures.

\section{Results}

Sample demographics were as follows: the mean age of the patient group and the healthy control group were 41.3 years $(\mathrm{SD}=8.9$ years $)$ and 48.7 years $(\mathrm{SD}=15.7$ years $)$, respectively. The education level of the majority $(65.2 \%)$ of the patient group consisted of senior high school and $69.6 \%$ were single; $64.5 \%$ of the healthy control group had a university degree and $74.2 \%$ were married. Clinical characteristics of the patient and control groups are shown in Table 1. Correlations of sociodemographic variables, neuropsychological variables, self-esteem, internal health locus of control, and external health locus of control are presented in Table 2. For all patients, the equivalent dosage of typical and atypical antipsychotic medication converted to chlorpromazine was $336 \mathrm{mg}(\mathrm{SD}=66.19 \mathrm{mg})$. The medication dosage was not correlated with any sociodemographic or neuropsychological variables. The onset of illness was not correlated with gender, education, neuropsychological variables, or clinical measures. Only significant variables are shown in Table 2.

The aim was to understand the extent to which sociodemographic and neuropsychological factors were independently related to self-esteem, internal health locus of control, and external health locus of control. Two or three stepwise multiple regression analyses were performed, as shown in Table 1, allowing significant variables that are related to the dependent variables to enter the assessment to predict selfesteem, internal health locus of control, and external health locus of control.

As summarized in Table 3, inhibition of attention and external health locus of control emerged to contribute significantly as predictors of subjects' self-esteem (adjusted $R^{2}=0.22, P<0.01$ ). Inhibition of attention and external health locus of control emerged as significant contributors to internal health locus of control (adjusted $\left.R^{2}=0.54, P<0.001\right)$. For external health locus of control, only education was a significant predictor (adjusted $R^{2}=0.08$, $P<0.05$ ). Table 3 presents the details of the beta weights of each contributing variable.

\section{Discussion}

Although the associations among various factors in this study had small effect sizes, background characteristics and main neuropsychological variables showed several significant relationships. The findings of this study provide evidence that inhibition of attention and external locus of control were associated with self-esteem in schizophrenia. Schizophrenia and poor attention were significantly associated with poor self-esteem, which is consistent with previous studies. ${ }^{24,26}$ With regard to health locus of control, previous research suggested that people with external control orientations demonstrated poor adjustment to illness and were less likely to find available resources to cope with problems. ${ }^{35-40}$ Within the sociodemographic factors, education was inversely related to external health locus of control, indicating that schizophrenia patients with higher education held less belief that their health status was the result of external factors (lower scores in external locus of control). Internal health locus of control was found to correlate negatively with inhibition of attention (variability of reaction time), suggesting that schizophrenic patients with higher internal health locus of control had a lower rate of impulse control. We also found that schizophrenia with better self-esteem was associated with higher external locus of control, implying their healthy behaviors were determined by powerful others and chance. The above findings were not consistent with the research of Goodman et al, ${ }^{41}$ who found that lower self-esteem scores were significantly correlated with higher levels of external control among female schizophrenics. It is probable that the discrepancies between findings may be because a majority of the sample group recruited in Goodman et al's ${ }^{41}$ study had an education level less than a senior high school degree, and the average age was younger, which may influence their self-esteem level. The present study also found that internal health locus of control was strongly associated with external health locus of control, which accounted for $37 \%$ of the variance of internal health locus of control.

In contrast, self-esteem in the healthy control group was positively correlated with internal health locus of control and negatively correlated with external health locus of control. This 
Table I Sociodemographic and clinical characteristics of patient group and healthy control group

\begin{tabular}{|c|c|c|c|}
\hline & $\begin{array}{l}\text { Patient group } \\
n=46\end{array}$ & $\begin{array}{l}\text { Healthy control group } \\
n=3 \text { I }\end{array}$ & $P$-value \\
\hline \multicolumn{4}{|l|}{ Neurocognitive performances } \\
\hline \multicolumn{4}{|l|}{ Executive functioning } \\
\hline \multicolumn{4}{|l|}{ General performance measures } \\
\hline Total correct responses & $61.4(25.1)$ & $73.1(10.1)$ & 0.017 \\
\hline Total response errors & $46.5(21.2)$ & $29.8(19.0)$ & $0.000^{*}$ \\
\hline Total categories completed & $3.0(2.29)$ & $5.3(1.3)$ & $0.000 *$ \\
\hline \multicolumn{4}{|l|}{ Perseveration } \\
\hline Perseverative responses & $30.3(23.1)$ & $15.3(9.7)$ & $0.000 *$ \\
\hline Perseverative errors & $28.3(20.9)$ & I $3.7(8.4)$ & $0.000 *$ \\
\hline \multicolumn{4}{|l|}{ Conceptual ability } \\
\hline Trials to complete first category & $24.9(22.7)$ & I7.I (9.1) & 0.084 \\
\hline Conceptual level responses & $41.5(23.7)$ & $66.9(17.8)$ & $0.000 *$ \\
\hline Immediate face recognition memory & $7.8(3.3)$ & II.2 (3.I) & $0.00 I^{*}$ \\
\hline Verbal paired associations memory & $5.6(3.3)$ & $9.9(2.7)$ & $0.000 *$ \\
\hline \multicolumn{4}{|l|}{ Digit span } \\
\hline Forward & $10.0(2.7)$ & II.7 (2.2) & 0.052 \\
\hline Backward & $8.1(3.3)$ & $10.8(3.2)$ & 0.051 \\
\hline Total & $9.3(3.0)$ & $11.5(3.1)$ & 0.197 \\
\hline \multicolumn{4}{|l|}{ Spatial span } \\
\hline Forward & $9.0(3.3)$ & $9.9(2.7)$ & 0.969 \\
\hline Backward & $7.3(3.0)$ & $8.4(2.4)$ & 0.931 \\
\hline Total & $7.5(3.3)$ & $9.2(2.5)$ & 0.447 \\
\hline \multicolumn{4}{|l|}{ Alertness } \\
\hline \multicolumn{4}{|l|}{ Without warning } \\
\hline Median of reaction time (in ms) & $422.4(274.9)$ & $368.3(163.5)$ & 0.073 \\
\hline Variability of reaction time (in ms) & $106.6(102.3)$ & $83.5(74.8)$ & 0.140 \\
\hline \multicolumn{4}{|l|}{ With warning } \\
\hline Median of reaction time (in ms) & $361.9(198.6)$ & 334.5 (I25.9) & 0.201 \\
\hline Variability of reaction time (in ms) & $79.6(78.1)$ & $58.0(39.7)$ & 0.036 \\
\hline \multicolumn{4}{|l|}{ Crossmodal integration } \\
\hline Number of errors & $4.2(5.3)$ & $0.6(1.1)$ & $0.001 *$ \\
\hline Number of omission & $2.0(2.8)$ & $0.8(1.1)$ & 0.012 \\
\hline \multicolumn{4}{|l|}{ Flexibility } \\
\hline \multicolumn{4}{|l|}{ Letter } \\
\hline Number of correct & $46.9(3.44)$ & $48.9(1.5)$ & 0.007 \\
\hline Number of errors & I.4 (I.6) & $0.5(0.7)$ & 0.008 \\
\hline Median of reaction time (in ms) & $625.9(226.4)$ & $520.9(121.2)$ & $0.000^{*}$ \\
\hline \multicolumn{4}{|l|}{ Number } \\
\hline Number of correct & $47.6(3.5)$ & $49.6(0.7)$ & $0.003 *$ \\
\hline Number of errors & I.I (I.7) & $0.1(0.3)$ & 0.004 \\
\hline Median of reaction time (in ms) & $663.7(228.7)$ & $508.2(87.0)$ & $0.000 *$ \\
\hline \multicolumn{4}{|l|}{ Go/no-go I-2 } \\
\hline Number of errors & $5.0(4.3)$ & $2.1(1.7)$ & 0.005 \\
\hline Number of omission & $1.3(1.8)$ & $0.7(1.0)$ & 0.125 \\
\hline Median of reaction time (in ms) & $419.3(139.3)$ & $377.5(80.4)$ & 0.007 \\
\hline Variability of reaction time (in ms) & $101.7(59.1)$ & $77.5(26.5)$ & 0.016 \\
\hline \multicolumn{4}{|l|}{ Go/no-go 2-5 } \\
\hline Number of errors & $6.3(7.2)$ & $2.3(3.9)$ & 0.094 \\
\hline Number of omission & $3.8(5.1)$ & $2.6(4.4)$ & 0.217 \\
\hline Median of reaction time (in $\mathrm{ms}$ ) & $637.9(134.9)$ & $600.9(87.5)$ & 0.033 \\
\hline Variability of reaction time (in ms) & $155.9(84.9)$ & $118.6(53.5)$ & 0.047 \\
\hline \multicolumn{4}{|l|}{ Incompatibility } \\
\hline Number of errors & $7.7(8.5)$ & $4.1(5.8)$ & 0.183 \\
\hline$F$ (visual field) & $3.5(3.8)$ & $4.1(5.9)$ & 0.544 \\
\hline$F$ (hand) & $2.1(3.12)$ & $2.5(2.9)$ & 0.684 \\
\hline$F$ (visual field $\times$ hand $)$ & $12.5(14.4)$ & $19.1(20.3)$ & 0.371 \\
\hline
\end{tabular}


Table I (Continued)

\begin{tabular}{llll}
\hline & $\begin{array}{l}\text { Patient group } \\
\mathbf{n = 4 6}\end{array}$ & $\begin{array}{l}\text { Healthy control group } \\
\mathbf{n = 3}\end{array}$ & P-value \\
\hline Clinical characteristics & & & \\
Self-esteem & $22.8(3.8)$ & $24.0(2.5)$ & 0.519 \\
Internal health locus of control & $20.6(3.8)$ & $23.0(2.4)$ & 0.004 \\
External health locus of control & $15.2(3.4)$ & $13.1(2.3)$ & 0.060 \\
\hline
\end{tabular}

Note: $* P<0.003$ (Bonferroni corrected).

Abbreviation: ms, milliseconds.

discrepancy and the higher correlation between the internal health locus of control and external health locus of control may have resulted from the illness attribution biases provided by the patients or their relatives. For example, it is probable that patients or relatives may explain the occurrence of their illness as an accident and not of their own responsibility, or accept medical assistance and religion to help provide them with normal functioning and to maintain self-esteem; all of which correlate with internal health locus of control. The present study investigated self-esteem and health locus of control with respect to sociodemographic characteristics and neuropsychological variables, and found that only inhibition of attention, external health locus of control, and education were associated with self-esteem, internal health locus of control, and external health locus of control. The predicted variance accounted for by inhibition of attention and education on self-esteem and external health locus of control was small $\left(\Delta \mathrm{R}^{2}=0.09\right.$, $\left.\Delta \mathrm{R}^{2}=0.10\right)$, respectively. It is probable that additional factors not included in this study may better relate to self-esteem and external health locus of control. Research findings thus suggest that individuals with a high sense of mastery, better health, emotional stability, extraversion, and conscientiousness experience higher self-esteem. ${ }^{42}$

Compared to the healthy control group, schizophrenic patients in this study showed more deficits on some neuropsychological variables. This result was consistent with previous reports of schizophrenia exhibiting cognitive impairment. ${ }^{27,28}$ In accordance with Bentall et al's ${ }^{1}$ findings, the results of the present study also showed that schizophrenic patients did not differ in their level of self-esteem when compared to the healthy control group. Although previous research showed that lower self-esteem correlated with mental suffering among patients under the schizophrenia spectrum disorder, ${ }^{8-10}$ few of these studies made comparisons between the self-esteem scores of a patient group to a healthy control group. Although we did not separate the schizophrenic patients into subtypes, most of the patients recruited were in the remitted paranoid stage. Possible explanations in the different maintenance of self-esteem can be referred to several theories of paranoia, psychological models of symptom development, relatives' reactions, and self-reference effect. ${ }^{24,42-44}$

Table 2 Correlations among sociodemographic variables, neuropsychological variables, self-esteem, internal health locus of control, and external health locus of control $(n=46)$

\begin{tabular}{|c|c|c|c|c|c|c|c|c|c|c|c|c|}
\hline & Variables & & & & & & & & & & & \\
\hline & $\begin{array}{l}\text { Illness of } \\
\text { duration }\end{array}$ & PR & PE & SSB & AMO & AMW & AVO & AOW & FLM & FNM & GIM & G2M \\
\hline \multirow[t]{2}{*}{ I. Age } & $0.62 * *$ & $0.40 * *$ & $0.36 * *$ & $0.39 * *$ & $0.43 * *$ & $0.33^{*}$ & $0.44 * *$ & $0.30 *$ & $0.45^{* *}$ & $0.38 * *$ & $0.42 * *$ & $0.43 * *$ \\
\hline & DSB & DS & SSB & SS & AMO & AMW & AVO & GIM & & & & \\
\hline \multirow[t]{2}{*}{ 2. Illness of duration } & $0.34 *$ & $0.35^{*}$ & $0.33 *$ & $0.31 *$ & $0.30 *$ & $0.31 * *$ & $0.45^{*}$ & $0.30 *$ & & & & \\
\hline & EHLC & & & & & & & & & & & \\
\hline \multirow[t]{2}{*}{ 3. Education } & $-0.3 I^{*}$ & & & & & & & & & & & \\
\hline & TCC & GIV & IHLC & EHLC & & & & & & & & \\
\hline \multirow[t]{2}{*}{ 4. SE } & $0.30 *$ & $-0.30 *$ & $0.49 * *$ & $0.4 I^{* *}$ & & & & & & & & \\
\hline & GIV & EHLC & & & & & & & & & & \\
\hline \multirow[t]{2}{*}{ 5. IHLC } & $0.43 * *$ & $0.62 * *$ & & & & & & & & & & \\
\hline & Education & SSB & & & & & & & & & & \\
\hline 6. EHLC & $-0.3 I^{*}$ & $-0.3 I^{*}$ & & & & & & & & & & \\
\hline
\end{tabular}

Notes: $* P<0.05 ; * * P<0.01$.

Abbreviations: AMO, median of reaction time of alertness (without warning); AMW, median of reaction time of alertness (with warning); AOW, variability of reaction time of alertness (with warning); AVO, variability of reaction time of alertness (without warning); DS, digit span; DSB, digit span backward; EHLC, external health locus of control; FLM, median of reaction time of flexibility (letter); FNM, median of reaction time of flexibility (number); GIM, median of reaction time of inhibition of attention (go/no-go I-2); GIV, variability of reaction time of inhibition of attention (go/no-go I-2); G2M, median of reaction time of inhibition of attention (go/no-go 2-5); IHLC, internal health locus of control; PR, perseverative responses; PE, perseverative errors; SE, self-esteem; SS, spatial span; SSB, spatial span backward; TCC, total categories completed. 
Table 3 Multiple regressions predicting self-esteem, internal health locus of control, and external health locus of control scores from sociodemographic and neuropsychological variables $(n=46)$

\begin{tabular}{|c|c|c|c|c|c|}
\hline Measure & $\begin{array}{l}\text { Contributing sociodemographic } \\
\text { and neuropsychological variables }\end{array}$ & Beta & $t$ & $\Delta R^{2}$ & $\boldsymbol{F}_{\text {change }}$ \\
\hline \multirow[t]{2}{*}{ Self-esteem } & Inhibition of attention (go/no-go I-2) & -0.30 & -2.09 & 0.09 & $4.59 *$ \\
\hline & External health locus of control & 0.41 & 3.13 & 0.16 & $9.85 * *$ \\
\hline \multirow[t]{2}{*}{ Internal health locus of control } & Inhibition of attention (go/no-go I-2) & -0.43 & -3.21 & 0.19 & $10.35 * *$ \\
\hline & External health locus of control & 0.61 & 6.06 & 0.37 & $36.80 * * *$ \\
\hline External health locus of control & Education & -0.31 & -2.21 & 0.10 & $4.90^{*}$ \\
\hline
\end{tabular}

Notes: $* p<0.05 ; * * p<0.01 ; * * * p<0.001$.

Gender differences in the neurocognitive functioning of the schizophrenic patients were observed only in immediate face recognition memory and attention, including number of errors of crossmodal integration and number of omissions of inhibition. Females displayed better performance in immediate face recognition memory, poor scores in number of errors of crossmodal integration and lower scores in number of omissions of inhibition. Consistently, Han et al ${ }^{27}$ also found that male schizophrenic patients had more serious cognitive deficits than females in immediate and delayed memory. Results by Bozikas et $\mathrm{l}^{45}$ found that female schizophrenics outperformed men only in verbal learning and memory, while the genders were consistent in ability on other cognitive domains (including inhibition, executive function, visual memory, visuospatial skills, and psychomotor speed). The cross-sectional nature of our study did not allow us to test the causal effect of sociodemographic characteristics or neuropsychological variables with self-esteem and health locus of control in schizophrenia; thus, prospective longitudinal study designs and larger samples are required to replicate findings.

In the present study, inhibition of attention and external health locus of control explained the variance of self-esteem. Inhibition of attention and external health locus of control were significant predictors of internal health locus of control, and education was negatively associated with external health locus of control. These findings also have implications for psychosocial interventions and cognitive training in schizophrenia. Given the impact of inhibition of attention, external health locus of control, and education on self-esteem, internal health locus of control, and external health locus of control, increasing importance should be placed on developing effective treatments or psychoeducation on the improvement of self-esteem and health locus of control among schizophrenic patients. ${ }^{46}$

\section{Acknowledgment}

This study was supported by a grant from Zuoying Armed Forces General Hospital, Kaohsiung, Taiwan (ZAFGH101-17).

\section{Disclosure}

The authors report no conflicts of interest in this work.

\section{References}

1. Bentall RP, Rowse G, Rouse G, et al. Paranoid delusions in schizophrenia spectrum disorders and depression: the transdiagnostic role of expectations of negative events and negative self-esteem. J Nerv Ment Dis. 2008;196(5):375-383.

2. Ritsner MS, Blumenkrantz H. Predicting domain-specific insight of schizophrenia patients from symptomatology, multiple neurocogitive functionings, and personality related traits. Psychiatry Res. 2007;149(1-3):59-69.

3. Vauth R, Klein B, Wirtz M, Corrigan PW. Self-efficacy and empowerment as outcomes of self-stigmatizing and coping in schizophrenia. Psychiatry Res. 2007;150(1):71-80.

4. Freeman D, Garety P, Fowler D, et al. The London-East Anglia randomized controlled trial of cognitive-behaviour therapy for psychosis. IV: Self-esteem and persecutory delusions. Br J Clin Psychol. 1998; 37(Pt 4):415-340.

5. Garety PA, Kuipers E, Fowler D, Freeman D, Bebbington PE. A cognitive model of the positive symptoms of psychosis. Psychol Med. 2001;31(2):189-195.

6. Markowitz FE. Modeling process in recovery from mental illness: relationship between symptoms, life satisfaction, and self-concept. J Health Soc Behav. 2001;42(1):64-79.

7. Brown GW, Bifulco A, Veiel HO, Andrews B. Self-esteem and depression. II. Social correlates of self-esteem. Soc Psychiatry Psychiatr Epidemiol. 1990;25(5):225-234.

8. Bhar S, Ghahramanlou-Holloway M, Brown G, Beck AT. Self-esteem and suicide ideation in psychiatric outpatients. Suicide Life Threat Behav. 2008;38(5):511-516.

9. Karatzias T, Gumley A, Power K, O’Grady M. Illness appraisals and self-esteem as correlates of anxiety and affective comorbid disorders in schizophrenia. Compr Psychiatry. 2007;48(4):371-375.

10. Roe D. A prospective study on the relationship between self-esteem and functioning during the first year after being hospitalized for psychosis. J Nerv Ment Dis. 2003;191(1):45-49.

11. Brown GW, Bifulco A, Andrews B. Self-esteem and depression. IV. Effect on course and recovery. Soc Psychiatry Psychiatr Epidemiol. 1990;25(5):244-249.

12. Silverstone PH. Low self-esteem in different psychiatric conditions. $\mathrm{Br}$ J Clin Psychol. 1991;30( Pt 2):185-188.

13. Bartels A, Zeki S. The neural basis of romantic love. Neuroreport. 2000;11(17):3829-3834.

14. Crocker J, Park LE. Seeking self-esteem: construction, maintenance and protection of self-worth. In: Leary MR, Tangney JP, editors. Handbook of Self and Identity. New York: Guilford Press; 2003: 291-313.

15. Dodgson PG, Wood JV. Self-esteem and the cognitive accessibility of strengths and weakness after failure. J Pers Soc Psychol. 1998;75(1): $178-197$. 
16. Linville PW. Self-complexity as a cognitive buffer against stress-related illness and depression. J Pers Soc Psychol. 1987;52(4):663-676.

17. Setliff AE, Marmurek HHC. The mood regulatory functioning of aerobiological recall is moderated by self-esteem. Pers Indiv Differ. 2002;32(4):761-771.

18. Fung KM, Tsang HW, Corrigan PW. Self-stigma of people with schizophrenia as predictor of their adherence to psychosocial treatment. Psychiatr Rehabil J. 2008;32(2):95-104.

19. Tsang HW, Fung KM, Corrigan PW. Psychosocial and sociodemographic correlates of medication compliance among people with schizophrenia. J Behav Ther Exp Psychiatry. 2009;40(1):3-14.

20. Luszczynska A, Schwarzer R. Multidimensional health locus of control: comments on the construct and its measurement. J Health Psychol. 2005;10(5):633-642.

21. Österman K, Björkqvist K, Lagerspetz KMJ, Charpentier S, Caprara GV, Pastorelli C. Locus of control and three types of aggression. Aggress Behav. 1999;25(1):61-65.

22. Wallston KA, Maides S, Wallston BS. Health-related information seeking as a function of health-related locus of control and health value. J Res Pers. 1976;10(2):215-222.

23. Buhagiar K, Parsonage L, Osborn DP. Physical health behaviours and health locus of control in people with schizophrenia-spectrum disorder and bipolar disorder: a cross-sectional comparative study with people with non-psychotic mental illness. BMC Psychiatry. 2011;11:104.

24. Wittorf A, Wiedemann G, Buchkremer G, Klingberg S. Quality and correlates of specific self-esteem at the beginning stabilisation phase of schizophrenia. Psychiatry Res. 2010;179(2):130-138.

25. Brekke, JS, Kohrt B, Green MF. Neuropsychological functioning as a moderator of the relationship between psychosocial functioning and the subjective experience of self and life in schizophrenia. Schizophr Bull. 2001;27(4):697-708.

26. Lysaker PH, Vohs JL, Tsai J. Negative symptoms and concordant impairments in attention in schizophrenia: associations with social functioning, hope, self-esteem and internalized stigma. Schizophr Res. 2009;110(1-3):165-172.

27. Han M, Huang XF, Chen da C, et al. Gender differences in cognitive functioning of patients with chronic schizophrenia. Prog Neuropsychopharmacol Biol Psychiatry. 2012;39(2):358-363.

28. Torniainen M, Suvisaari J, Partonen T, et al. Cognitive impairments in schizophrenia and schizoaffective disorder: relationship with clinical characteristics. J Nerv Ment Dis. 2012;200(4):316-322.

29. Spitzer R, Williams J, Gibbon M, First M. Structured Clinical Interview for DSM- IV. New York: Biometrics Research; 1994.

30. Rosenberg M. Society and the Adolescent Self-Image. Princeton: Princeton University Press; 1965.

31. Yu HF, Guo NW, Chen HY, Liang CP. [Factors affecting stroke patients' motivations for rehabilitation]. Gaoxiong Yi Xue Ke Xue Za Zhi. 1993;9(5):305-316. Chinese.
32. Heaton RK, Chelune GJ, Talley JL, Kay GG, Curtiss G. Wisconsin Card Sorting Test Manual: Revised and Expanded. Odessa: Psychological Assessment Resources Inc; 1993.

33. Wechsler D. Wechsler Memory Scale-Third Edition Manual. San Antonio, TX: The Psychological Corporation; 1997.

34. Zimmermann P, Fimm B. A test battery for attentional performance. In: Leclercq M, Zimmermann P, editors. Applied Neuropsychology of Attention: Theory, Diagnosis and Rehabilitation. New York: Psychology Press; 2002:110-151.

35. Burker EJ, Evon DM, Galanko J, Egan T. Health locus of control predicts survival after lung transplant. J Health Psychol. 2005;10(5):695-704.

36. Crisson JE, Keefe FJ. The relationship of locus of control to pain coping strategies and psychological distress in chronic pain patients. Pain. 1988;35(2):147-154.

37. Härkäpää K. Psychosocial factors as predictors for early retirement in patients with chronic low back pain. J Psychosom Res. 1992;36(6): 553-559.

38. Kist-Kline G, Lipnickey SC. Health locus of control: implications for the health professional. Health Values.1989;13(5):38-47.

39. Nyland J, Johnson DL, Caborn DN, Brindle T. Internal health status belief and lower perceived functional deficit are related among anterior cruciate ligament-deficient patients. Arthroscopy. 2002;18(5): 515-518.

40. Pucheu S, Consoli SM, D’Auzac C, Français P, Issad B. Do health causal attributions and coping strategies act as moderators of quality of life in peritoneal dialysis patients? J Psychosom Res. 2004;56(3):317-322.

41. Goodman SH, Cooley EL, Sewell DR, Leavitt N. Locus of control and self-esteem in depressed, low-income African-American women. Community Ment Health J. 1994;30(3):259-269.

42. Erol RY, Orth U. Self-esteem development from age 14 to 30 years: a longitudinal study. J Pers Soc Psychol. 2011;101(3):607-619.

43. Barrowclough C, Tarrier N, Humphreys L, Ward J, Gregg L, Andrews B. Self-esteem in schizophrenia: relationships between selfevaluation family attitudes, and symptomology. J Abnorm Psychol. 2003;112(1):92-99.

44. Pauly K, Kircher T, Weber J, Schneider F, Habel U. Self-concept, emotion and memory performance in schizophrenia. Psychiatry Res. 2011;186(1):11-17.

45. Bozikas VP, Kosmodis MH, Peltekis A, et al. Sex differences in neuropsychological functioning among schizophrenia patients. Aust $N Z J$ Psychiatry. 2010;44(4):333-341.

46. Borras L, Boucherie M, Mohr S, Lecomte T, Perroud N, Huquelet P. Increasing self-esteem: efficacy of a group intervention for individuals with severe mental disorders. Eur Psychiatry. 2009;24(5):307-316.
Neuropsychiatric Disease and Treatment

\section{Publish your work in this journal}

Neuropsychiatric Disease and Treatment is an international, peerreviewed journal of clinical therapeutics and pharmacology focusing on concise rapid reporting of clinical or pre-clinical studies on a range of neuropsychiatric and neurological disorders. This journal is indexed on PubMed Central, the 'PsycINFO' database and CAS.
Dovepress

The manuscript management system is completely online and includes a very quick and fair peer-review system, which is all easy to use. Visit $\mathrm{http}: / / \mathrm{www}$.dovepress.com/testimonials.php to read real quotes from published authors. 